\title{
CRYPTOCURRENCY AND CLIMATE CHANGE: AN OVERVIEW
}

\author{
Egiyi, Modesta Amaka \\ Godfrey Okoye University, Nigeria \\ Ofoegbu, Grace Nyereugwu \\ Department of Accountancy, Faculty of Business Administration \\ University of Nigeria, Nsukka, Nigeria
}

\begin{abstract}
Cryptocurrencies in recent years, have emerged as an innovative means of carrying out online financial transactions, but concerns have been raised among experts about their impact on our environmental. Cryptocurrencies place enormous demand on the energy system, and this increases carbon emissions which sequentially adds up to the overall effects of global warming. However, the technology that powers bitcoin (blockchain) should be considered for future adoption. The environmental hazard regarding cryptocurrency usage stems from the large carbon footprint left by such small share of global cashless transactions, and its potential to be broadly integrated into current technologies. This study examines the impact of cryptocurrency on the environment with its focus on climate change (Global warming). Although the fate of bitcoin is currently unpredictable, it can be projected that if its rate of adoption is accelerated, its electricity demand is capable of producing sufficient emissions to surpass $2^{\circ} \mathrm{C}$ of global warming in a few decades. The study recommends that further development in cryptocurrencies should analytically aim to reduce power demand so as to avoid the potentially demoralizing consequences of $2^{\circ} \mathrm{C}$ of global warming.
\end{abstract}

Keywords: Cryptocurrency; Climate Change; Block Chain.

Cite this Article: Egiyi, Modesta Amaka and Ofoegbu, Grace Nyereugwu, Cryptocurrency and Climate Change: An Overview. International Journal of Mechanical Engineering and Technology. 11(3), 2020, pp. 15-22.

https://iaeme.com/Home/issue/IJMET?Volume=11\&Issue=3

\section{INTRODUCTION}

Presently, bitcoin has recorded 10 years of existence which could be considered as a major milestone for a technology that was predicted to never come into prominence. However, regardless of the major landmarks achieved by the world's most popular cryptocurrency, a lot of concerns have been raised regarding the heavy hardware and power consumption requirements of Bitcoin mining and its consequent impact on our environment (Lin et al, 
2017). Over the years, bitcoin has been subjected to a lot of criticisms based on the outrageous amount of energy required for its production. According to Stephen (2017), bitcoin is fast becoming a real-world environmental disaster. This assertion was based on the cost of the bitcoin mining process which consumed well over $\$ 150,000$ worth of electricity in a day. The criticisms have grown louder with the mining of more coins which have increased from approximately 11 million in the year 2013 to over 17 million as at 2018. Compared to other conventional digital monetary or financial activities, it has been observed that the electricity consumption of Bitcoin mining has been on the high side since 2015. According to Christopher (2017), the dollar price of Bitcoin is directly proportional to the cost of electricity that is required to profitably mine it.

According to the Wall Street Journal, Bitcoin is the world's hottest Currency, but no one is making use of it. Earlier on, the value of bitcoin had pitched up to $\$ 10,000$ per coin and even extended to $\$ 11,000$ at a certain time (Kantchev, Russolillo, Vigna, \& Whittall, 2017). But despite the surge in bitcoin's value, local and conventional stores have been slow to accept it as a payment method (Russolillo, 2018). Hence, the pessimistic outlook of observers with regards to this tech-hipster cryptocurrency, which despite its popularity and controversy, stands a very slim chance of replacing the traditional currency. According to the report, bitcoin and its likes might never become mainstream traditional currencies with reasons being that if it eventually becomes a currency, it will lose its value as an investment asset. This poses a serious problem because inasmuch as bitcoin is not being used by people, we still pay for them. According to reports by Alex de Vries a bitcoin analyst, otherwise known as the Digiconomist, the surge in bitcoin triggered an increase in its estimated annual energy depletion from 25 Terawatt hours to 30 Terawatt hours within two months which is equivalent to the energy use of more than 19 European countries (Dwyer \& Malone, 2014), and approximately 0.7 percent of total energy requirement in the United States, which is equal to the energy consumption of 2.8 million U.S. households (Atkin, 2017).

The mining process of bitcoin requires enormous amounts of electricity and this results in the release of large amounts of $\mathrm{CO}^{2}$ into the atmosphere. The year 2017 alone, recorded approximately 69 million metric tons of $\mathrm{CO}^{2}$ (Carbon dioxide) emission as a result of bitcoin mining. One blockchain mining transaction can consume as much energy as an entire household requires in a week, not to mention about 300,000 transactions carried out on a daily basis. That high amount of energy demand is more often met by fossil fuel energy sources, which end up polluting both air and water, as well as generate greenhouse gas emissions that cause climate change.

\section{CLIMATE CHANGE AND ITS EFFECT}

Solar radiations from the sun are balanced by the thermal radiations emanating from the earth's this energy balance determines the earth's surface temperature. The incoming solar radiation depends on the solar output and the earth's distance from the sun, and is independent of the surface temperature of the earth. On the other hand, the outgoing thermal radiation from the earth strongly depends on the earth's surface temperature. If the atmosphere was composed only of nitrogen and oxygen molecules, which do not absorb thermal radiation, the earth's surface temperature would be controlled to about $-6^{\circ} \mathrm{C}$ by the energy balance (Aizebeokhai, 2009). This surface temperature would render much of the planet frozen. The natural abundance of greenhouse gases in the atmosphere which majorly consists of water vapor, carbon dioxide and methane traps some of the outgoing thermal radiation, thereby creating a new energy equilibrium with a surface temperature of about $15^{\circ} \mathrm{C}$. This phenomenon, which amounts to $21^{\circ} \mathrm{C}$ warming of the earth's surface, is usually called natural or beneficial greenhouse effect (Aizebeokhai, 2009). 
Greenhouse gases are emitted as a result of human activities. Carbon dioxide is the first and most prominent in the list of greenhouse gasses. Excess burning of fossil fuels such as coal and petroleum are the major causes of carbon production. Furthermore, deforestation or removal of trees for the purpose of acquiring lands for agricultural purposes and industrial activities also contribute to the large quantity of carbon dioxide in the atmosphere. The manufacture of cement also contributes to increased level of carbon dioxide in the atmosphere which happens when calcium carbonate is heated to produce lime and carbon dioxide. Methane commonly known as natural gas is the second greenhouse gas found in the atmosphere. It is produced from agricultural activities like paddy rice farming and use of farmyard manure. It is also produced as a result of improper waste management. Nitrous oxides are created mainly by fertilizers. Moreover, several industrial processes like refrigeration lead to the production of gases such as chlorofluorocarbons (CFCs) (EPA, 2015). The major sources contributing to the increasing absorption of carbon dioxide in the earth's atmosphere include the burning of fossil fuels. Annually, about 5.4 billion metric tons of carbon is emitted into the atmosphere from the burning of fossil fuels. Also, deforestation accounts for about 1.6 billion metric tons of carbon emitted into the atmosphere (Marland, Boden, \& and Andres, 2005).

Greenhouse gases are the major cause of global warming. Alongside the major greenhouse gases (Methane, $\mathrm{CO}^{2}$ and Nitrous Oxides), chlorine and bromine containing compounds also contribute to the greenhouse effect. The accumulation of these gases in the atmosphere alters the radiative equilibrium in the thermosphere which eventually warms the Earth's surface and the lower atmosphere. This is because the greenhouse gases absorb a percentage of the outgoing radiation from Earth and channels it back towards the earth's surface. It has been observed that the net warming from 1850 to the fall of the 20th century was nearly $2.5 \mathrm{~W} / \mathrm{m}^{2}$ with carbon dioxide contributing approximately $60 \%$, methane about 25 per cent, while nitrous oxides and halocarbons constitute the remainder., Joe Farman, of the British Antarctic Survey, published an article in 1985 revealing the depletion in ozone levels in the Antarctica during the early 1980s. This led to international scientific programmes which were embarked upon. These scientific programs ascertained that Chloro-Floro Carbons (which were mainly used as aerosol propellants in refrigeration tools and also as industrial cleaning fluids) were the chief cause of the problem. This let to abrupt international action to curtail the emissions of CFCs. It was also established that apart from CFCs, the depletion of ozone layer is the second major cause of global warming.

Modern day global warming is as a result of the increase in the amount of the greenhouse gasses present in the atmosphere, which has increased warming of the Earth and lower atmosphere triggered by the presence of $\mathrm{CO}^{2}$, methane, water-vapour and other greenhouse gases. It was reported in 2014 by the IPCC that the concentration of greenhouse gases in the atmosphere exceeded those in ice cores dating back to 800,000 years ago (David \& Eric, 2008). But carbon dioxide happens to be the most significant of all these gases due to its role in the greenhouse effect and also for the role it plays in the human economy (Encyclopedia, 2018). Estimates show that the concentrated amount of carbon dioxide in the atmosphere was about 280 parts per million (ppm) at the onset of the industrial age in the mid-18th century (Clarifield, 2018). But currently, as at the 2018 they have risen up to $406 \mathrm{ppm}$. It has been projected to increase to $550 \mathrm{ppm}$ by the mid-21st century and if the current rate at which fossil fuels are burned continues, a doubling of carbon dioxide concentrations in 300 years will be recorded. 


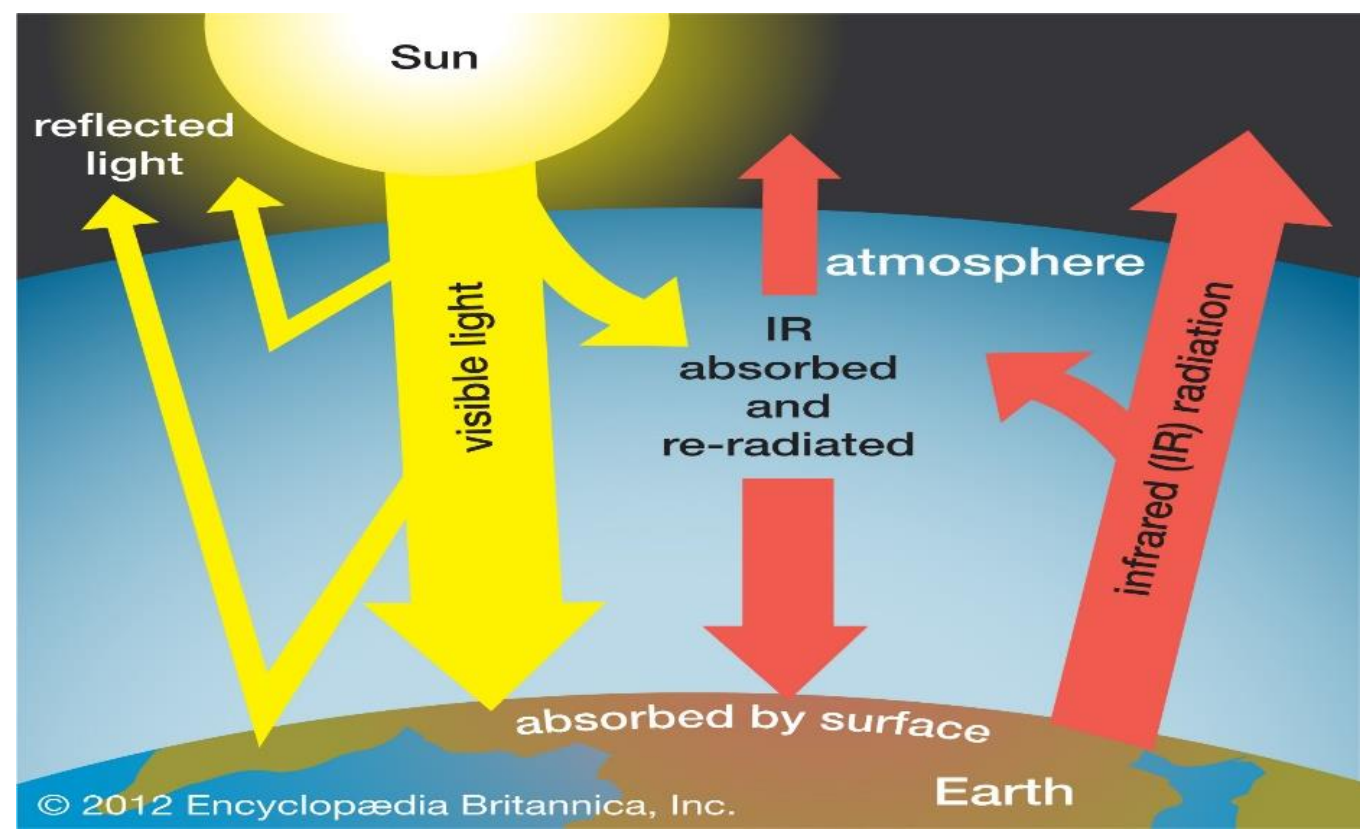

Figure 1 The Green House Effect on Earth.

Source: https://www.britannica.com/science/global-warming

The incoming rays of sunlight are reflected by the earth's surface while most of it, is absorbed by the atmosphere which is warmed. Infrared (IR) is then emitted from the earth's surface. Some infrared radiations escape to space but some are absorbed by the atmospheres' greenhouse gasses (especially, water, carbon dioxide and methane) and redirected to various directions, some to space while others are channeled back towards the earth's surface where it warms the lower atmosphere.

In terms of climate change, global warming is not a favourable phenomenon. According to a study the University of Hawaii at Manoa, if bitcoin continues its trail, it could generate sufficient emissions to raise global temperatures to $2^{\circ} \mathrm{C}$ by 2033. This is feasible if Bitcoin is adopted even at the lowest rate at which other technologies have been incorporated. (Dormehl, 2018). The researchers examined the power effectiveness of application specific integrated circuits (ASICs), which are currently used for Bitcoin mining after which they factored in the places where Bitcoin is likely computed and the equivalent $\mathrm{CO} 2$ emissions, with consideration of the electricity production fuels in those locations. It was gathered that the increased climate change of 2 degrees Celsius could lead to catastrophic and irreversible changes on earth.

The task of predicting the consequences of global warming is a difficult task encountered by the climate researchers owing to the fact that natural processes responsible for rise in sea levels, rain, snowfall and hailstorms are dependent on many diverse factors. Furthermore, the difficulty in predicting the size of greenhouse gas emissions in the future arises due to the fact that technological advancements and political policies play a major role in its determination. There are several negative effects produced by Global warming. To begin with, flooding is experienced in various regions of the world due to heavy and frequent precipitation as a result of additional water vapour present in the atmosphere. The warmer the weather, the higher the evaporation process from both land and water bodies which leads to drought in the areas where increased evaporation is not recompensed by increased precipitation. This results to crop failure and famine in certain parts of the world, predominantly in areas with higher temperature. Also, this causes the extra water vapour in the atmosphere to fall again as extra rain thereby causing incessant flooding. Regions which depend on the melting water from 
snowy mountains may experience drought and shortage of water supply because glaciers all over the world begin to shrink at a rapid rate and melting of ice becomes faster than previously projected. According to statistics from Intergovernmental Panel on Climate Change (IPCC), approximately one-sixth of the total world population live in these areas which will be affected by a decline in melting water. More heat waves are likely to be experienced in warmer climate regions alongside increased violent rainfall, severe hailstorms and thunderstorms (Chigbo, Chidozie, \& Nwozor, 2016). One of the most catastrophic effects of global warming is the rising of sea levels. This rise in temperature causes the ice and glaciers to melt rapidly which leads to a rise in water levels of oceans, rivers and lakes which triggers devastative floods (British Geological Survey, 2015).

The health of living things can be severely affected by the effects of global warming. Excessive heat causes stress which in turn leads to increased blood pressure and heart diseases. Also, famine and crop failures, which are direct results of heating up of the earth causes decline in the human body's resistance to viruses and infections (Hammon, 2010). The transfer of various diseases to other regions increases as people migrate from regions of higher temperatures to regions of relatively lower temperatures as a result of global warming. Cholera outbreaks and other harmful infections may arise from the consumption of some types of sea food as a result of warmer surface waters (Climate Hot Map, 2017).

\section{CRYPTOCURRENCY MINING AND ITS EFFECTS}

The inception of the Blockchain technology was spontaneous, and while the knowledge of this technology is popular, many others are still not well informed about it and how it affects them directly or indirectly (Dinh, et al., 2017). The impact of crypto mining on global warming is still unknown to many. Cryptocurrencies such as bitcoin are powered by the blockchain which is the database technology that powers the operation of cryptocurrencies like Bitcoin, Ethereum etc (Yang, Gavigan, \& Wilcox-O'Hearn, 2016). Since its introduction, it has steered a new course in many industries and efforts are being made to integrate this technology into banking and payment systems (Deloitte, 2016). Nonetheless, this technology has its downside which is the negative impact it has on our climate and global warming.

Generally, bitcoin mining is an automated process of finding a specific hash value that solves a block of transaction data and adding it to a growing chain of blocks that is known as the blockchain (Antonopoulos, 2014.). Mining is the process that secures this distributed ledger of transactions, but this is achieved at a high cost. Most successful cryptocurrency miners run warehouses full of specialized heavy power consuming machines constantly. The reward for solving these complex mathematical problems is the release of some new bitcoins to the miner, which makes it a potentially lucrative venture. Bitcoin Miners earn between US $\$ 7-\$ 9$ for processing each bitcoin transaction. In order to achieve this, they consume a huge amount of electricity power. The estimated amount of power consumed by bitcoin mining suggests an unsustainable future for Bitcoin as well as environmental disaster (Roberts, 2018). Bitcoin is applauded as a way out of a problem referred to as the Byzantine fault tolerance (Castro \& Linkov, 2002). By design, it is equipped with the solution to the problem of trust among participants in a transaction. Mining of virtual currencies involves an overwhelming amount of energy. The energy intensive process of obtaining new bitcoins and other cryptocurrencies enormously contributes to climate change. The first peer-reviewed study published in Joule revealed that bitcoin mining consumes an astounding 2.55 gigawatts which is equivalent to the energy consumed annually by Ireland. Even worse is the fact that this figure doubles every six months meaning that it will be responsible for about 0.3 percent of global energy use by the fall of 2018. 
In other words, cryptocurrency mining is adversely contributing to global warming without providing a substantial public benefit in return. The major reason for the hype in bitcoin and other cryptocurrencies is that most Bitcoin enthusiasts claim that it has the potential of becoming a mainstream currency in the nearest future and that the crypto governance system could have positive effects on the environment. But the present reality remains that the crypto currency market is volatile with a murky future. One of the downsides of bitcoin is that unlike cash, cryptocurrencies exist solely in digital form and cannot be printed. For bitcoin to be created, a power intensive task is involved which requires the solving of a complex math problem by a computer in the bitcoin network which is known as mining. Even so, the of Bitcoins that can be mined is limited to 21 million, and the more Bitcoins are mined, the more complex and complicated the math problems become. Thus, computers require more power to process more information thereby doing more work in order to solve the complex math problems which allow new bitcoins to be created.

Before now, mid-range personal computers were capable of mining bitcoins. But currently, owing to the complexity of the mathematical problems, specialized computer hardware known as Application Specific Integrated Circuit (ASIC) are required for crypto mining. These mining machines are large in size and generate heat, and the amount of electricity required to run these machines places a high financial burden on the individuals or companies engage in mining of cryptocurrency. In 2015, Vice profiled a Chinese Bitcoin mining facility that spent $\$ 80,000$ per month on electricity for these ASIC miners, in order to produce 4,050 bitcoins in the same period (Atkin, 2017). A study from the University of Cambridge earlier this year found that 58 percent of Bitcoin mining comes from China due to the availability of cheap power. Most of this form of cheap powers are dirty and in China, miners utilize low-cost coal generators. According to an analysis by De Vries, one cryptocurrency mine in China with an enormous amount of carbon footprint emitted carbon dioxide at the same rate as a Boeing 747 jumbo jet.

The growing use of bitcoin threatens a cataclysmic escalation of climate change. According to an analysis on the power efficiency of computers used for bitcoin mining by a team at the University of Hawaii Manoa (Mora, 2018), it was estimated that the activity was accountable for the emission of 69 million metric tonnes of $\mathrm{CO}^{2}$ in 2017 . They projected that if bitcoin is accepted at rates similar to other newfangled technologies, it is capable of raising global temperatures by $2^{\circ} \mathrm{C}$ within the next 22 years at a conservative rate, or even within 16 years in an extreme scenario. The study, which is published in the Nature Climate Change also revealed that apart from cryptocurrency's impact to global warming, the emissions from the transportation sector, housing and food are considered to be the main contributors to the ongoing adverse climatic changes (Scott-Briggs, 2018).

\section{CONCLUSION AND RECOMMENDATION}

According to Randi Rollins, a researcher who carried out a study on the effects of cryptocurrencies on the environment, despite the fact that cryptocurrency is an innovative and interesting technology (BSI, 2017), its mining system needs a change. He further outlined that cryptocurrency highlights a broader issue which has to do with emerging technologies and industries making smart decisions for development yet being aware of the consequences of emission on the environment. Hence, the adoption of green sustainable energy would allow the existence of cryptocurrencies without the adverse environmental repercussions involved.

Presently, the environmental hazards triggered by global warming are terrific. Disproportionate use of fossil fuels like natural gas, oil and coal are the major causes of these hazards. The use of fossil fuels should be stopped without further delay. Alternative clean sources of energy which include solar, wind, bio mass, geothermal and hydro should be 
adopted. These sources of energy do not produce toxic gases that cause pollution and cause global warming. These environmentally friendly energy sources do not threaten the ecological balance of the environment. However, the high cost of installation and setup required for their use poses a challenge for energy companies and individuals. Most significantly, fossil fuels are gradually depleting which necessitates a switch over to renewable sources for energy production. Thus, the ultimate solution required to put an end to global warming is to revert to alternative renewable energy sources. Public, in general, should be responsible about their decisions on energy conservation methods. This will ensure a healthy atmosphere and stable climate for our future generations. Governments should devise and pass policies which encourage the energy companies and people, in general, to use renewable energy instead of conventional energy.

As outlined in this work, the concept of cryptocurrency and the technology behind it poses no threat to the environment but the problem arises from the exorbitant energy requirements needed for its processing. In order to effectively control the hazards of global warming and climate change, the emission of greenhouse gases into the atmosphere should be drastically reduced. This can be achieved by improving energy conservation and production as well as enhancing efficient utilization of non-fossil fuels. The use of non-fossil fuels can be greatly improved by employing high tech engineering and engaging economic and political entrepreneurs. This could fast track the transition from fossil fuels to greater use of renewable energy resources and non-fossil fuels. Technological development geared towards energy efficiency, renewable sources and non-fossil fuels could allow developing countries to avoid the carbon intensive energy production phase of industrialization. This approach can simultaneously reduce the disproportionate energy consumption in industrialized countries, thereby controlling global warming and climate change in the short-to-medium term. Other ways carbon dioxide emission could be reduced include establishment of stringent standards for power plants, development and marketing of high efficiency but cost-effective automobiles, and provision of financial incentives for energy efficiency in industries and homes.

\section{REFERENCES}

[1] Aizebeokhai, A. P. (2009). Global warming and climate change: Realities, International Journal of Physical Sciences, 4(13), 868-879.

[2] Antonopoulos, A. M. (2014.). Mastering Bitcoin: Unlocking Digital Cryptocurrencies, O'Reilly.

[3] Atkin, E. (2017). The Environmental Case Against Bitcoin. Crypto-Info. Retrieved from https://newrepublic.com/article/146099/environmental-case-bitcoin

[4] Atkin, E. (2017, December 5). The Environmental Case Against Bitcoin Mining the cryptocurrency requires a staggering amount of energy — contributing to global warming and providing little public benefit. Retrieved from The New Republic: https://newrepublic.com/article/146099/environmental-case-bitcoin

[5] BSI. (2017). Distributed Ledger Technologies/Blockchain: Challenges, opportunities and the prospects for standards. BSI.

[6] Chigbo, M., Chidozie, C. N., \& Nwozor, C. (2016). Industrialization and its Backlash: Focus on Climate Change and its Consequences. Science Alert, 1-3.

[7] Christopher, M. (2017). One Bitcoin Transaction Consumes As Much Energy As Your House Uses in a Week. Motherboard Journal, 1-2.

[8] Clarifield, S. (2018, December 12). Greenhouse Effect. Retrieved from Science Clarifield: http://www.scienceclarified.com/Ga-He/Greenhouse-Effect.html

[9] Climate Hot Map. (2017). Impacts of Global Warming. Retrieved from Climate Hot Map: http://www.climatehotmap.org/global-warmingeffects/health.html, 
[10] David, R. C., \& Eric, H. O. (2008). Carbon Dioxide sequestration. Elements: An international Magazine and Mineralogy, Geochemistry and patro;ogy, 4(5), 3-5.

[11] Deloitte. (2016). "Impacts of the Blockchain on fund distribution, Deloitte Luxembourg.

[12] Dinh, T. A., Liu, R., Zhang, M., Chen, G., Ooi, B. C., \& Wang, J. (2017). "Untangling Blockchain: A Data Processing View of Blockchain Systems. ArXiv, 1-20.

[13] Dormehl, L. D. (2018). If we want to slow down climate change, we should change how we mine Bitcoin. Emerging Tech.

[14] Encyclopedia. (2018, December 12). Greenhouse Effect. Retrieved from Encyclopedia.com: https://www.encyclopedia.com/science-and-technology/biology-andgenetics/environmental-studies/greenhouse-effect

[15] EPA. (2015, May 23). Greenhouse Gas Emissions. Retrieved from United States Environmental Protection Agency: http://www.epa.gov/climatechange/ghgemissions/,

[16] Hammon, K. (2010). How Does a Heat Wave Affect the Human Body. Scientific American Journal. Retrieved from https://www.scientificamerican.com/article/heat-wavehealth/

[17] Kantchev, G., Russolillo, S., Vigna, P., \& Whittall, C. (2017). Bitcoin Is the World's Hottest Currency, but No One's Using It. The Wall Street Journal, 1-2.

[18] M, C., \& B, L. (2002). Practical Byzantine Fault Tolerance and Proactive Recovery. ACM Transactions on Computer Systems, 20(4), 398-461

[19] Marland, G., Boden, T. A., \& and Andres, R. J. (2005). Global, Regional, and National CO2 Emissions. A Compendium of Data on Global Change, Carbon Dioxide Information. Oak Ridge, Tennessee. Analysis Center, Oak Ridge National Laboratory, U.S. Department of Energy

[20] Mora, C. (2018). Bitcoin can push global warming above $2{ }^{\circ} \mathrm{C}$ in a couple decades. University of Hawai.

[21] O, D. K., \& D, M. (2014). Bitcoin mining and its energy footprint. Limerick Ireland: Irish Signals and Systems Conference.

[22] Roberts, P. (2018). This Is What Happens When Bitcoin Miners Take Over Your Town. Politico Magazine. Retrieved from https://www.politico.com/magazine/story/2018/03/09/bitcoin-mining-energy-pricessmalltown-feature-217230

[23] Russolillo, S. (2018). Bitcoin's Hype Vanishes Just Like That: We're in the Boring Phase. Wall Street Journal.

[24] Scott-Briggs, A. (2018). The Blockchain Technology and its Impact on Global Warming. Retrieved from Tech Bullion: https://www.techbullion.com/the-blockchain-technologyand-its-impact-on-global-warming/

[25] Stephen, M. (2017). Bitcoin Is a High-Tech Dinosaur Soon to Be Extinct. Bloomberg Opinion, 1-3.

[26] Survey, B. G. (2015, May). Consequences of greenhouse effect temperature rises. Retrieved from British Geological Survey: http://www.bgs.ac.uk/discoveringGeology/climateChange/CCS/consequencesOfTemperat ureIncreas

[27] Y. P. Lin, J. R., Petway, A. J., H, M., S. W., L. C., Chou, \& F, H. (2017.). Blockchain: The Evolutionary Next Step for ICT E-Agriculture. Journal of Environments, 4(3).

[28] Yang, D., Gavigan, J., \& Wilcox-O'Hearn. (2016). Survey of confidentiality and privacy preserving technologies for blockchain. $R 3$. 